\title{
Nutrient profile of 23596 packaged supermarket foods and non-alcoholic beverages in Australia and New Zealand
}

\author{
Cliona Ni Mhurchu ${ }^{1, *}$, Ryan Brown ${ }^{2}$, Yannan Jiang ${ }^{1,2}$, Helen Eyles ${ }^{1}$, Elizabeth Dunford ${ }^{3}$ \\ and Bruce $\mathrm{Neal}^{3,4}$ \\ ${ }^{1}$ National Institute for Health Innovation, School of Population Health, University of Auckland, Private Bag 92019, \\ Auckland Mail Centre, Auckland 1 142, New Zealand: ${ }^{2}$ Department of Statistics, University of Auckland, Auckland, \\ New Zealand: ${ }^{3}$ Food Policy Division, The George Institute for Global Health, The University of Sydney, Sydney, \\ Australia: ${ }^{4}$ Division of Epidemiology and Biostatistics, School of Public Health, Imperial College, London, UK
}

Submitted 17 September 2014: Final revision received 23 February 2015: Accepted 2 March 2015: First published online 14 April 2015

\begin{abstract}
Objective: To compare the nutrient profile of packaged supermarket food products available in Australia and New Zealand. Eligibility to carry health claims and relationship between nutrient profile score and nutritional content were also evaluated.

Design: Nutritional composition data were collected in six major Australian and New Zealand supermarkets in 2012. Mean Food Standards Australia New Zealand Nutrient Profiling Scoring Criterion (NPSC) scores were calculated and the proportion of products eligible to display health claims was estimated. Regression analyses quantified associations between NPSC scores and energy density, saturated fat, sugar and sodium contents.

Results: NPSC scores were derived for 23596 packaged food products (mean score $7 \cdot 0$, range -17 to 53 ). Scores were lower (better nutrient profile) for foods in Australia compared with New Zealand (mean $6.6 v .7 \cdot 8$ ). Overall, $45 \%$ of foods were eligible to carry health claims based on NPSC thresholds: $47 \%$ in Australia and $41 \%$ in New Zealand. However, less than one-third of dairy (32\%), meat and meat products (28\%) and bread and bakery products $(27.5 \%)$ were eligible to carry health claims. Conversely, $>75 \%$ of convenience food products were eligible to carry health claims $(82.5 \%)$. Each two-unit higher NPSC score was associated with higher energy density $(78 \mathrm{~kJ} / 100 \mathrm{~g})$, saturated fat $(0.95 \mathrm{~g} / 100 \mathrm{~g})$, total sugar $(1.5 \mathrm{~g} / 100 \mathrm{~g})$ and sodium $(66 \mathrm{mg} / 100 \mathrm{~g}$; all $P$ values $<0.001)$.

Conclusions: Fewer than half of all packaged foods available in Australia and New Zealand in 2012 met nutritional criteria to carry health claims. The few healthy choices available in key staple food categories is a concern. Improvements in nutritional quality of foods through product reformulation have significant potential to improve population diets.
\end{abstract}

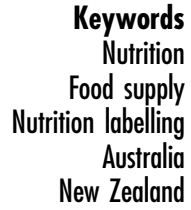

Good nutrition is essential for health, equity and prosperity. Collectively, dietary risk factors (high salt intake, high saturated fat intake, low vegetable and fruit intake, and excess energy intake) accounted for $11 \%$ of health loss in New Zealand in $2006^{(1)}$. Similarly, the leading risk factors for disease in Australia are related to $\operatorname{diet}^{(2)}$. Improving diets and reducing sodium intakes were identified as priorities for global action at the United Nations High-Level Meeting on non-communicable diseases in $2011^{(3)}$ and recommended by the WHO as 'best buys' for reducing deaths from non-communicable diseases ${ }^{(4)}$.

Processed foods contribute approximately threequarters of dietary energy and nutrients consumed in high-income countries ${ }^{(5)}$. Therefore, consumer food choices and the nutritional composition of processed foods have substantial potential to influence dietary intakes. Effective front-of-pack nutrition labelling has been identified as a potentially cost-effective strategy to improve population diets ${ }^{(6)}$ and health claims, which are present on substantial numbers of packaged, processed food products in New Zealand ${ }^{(7)}$ and Australia ${ }^{(8)}$, increase consumers' perceptions of the healthiness of packaged and processed foods ${ }^{(9,10)}$.

Nutrient profile models can be used to classify foods as 'healthy' and 'less healthy' based on their nutritional content $^{(11)}$. Nutrient profiling has been used to support 
nutrition labelling schemes, regulate the broadcast advertising of foods to children and regulate health claims on foods ${ }^{(11,12)}$. In 2009, a nutrient profiling model was proposed by the European Commission for regulation of nutrition and health claims on foods in the $\mathrm{EU}^{(13)}$.

In January 2013, a new Standard was introduced in Australia and New Zealand to regulate nutrition content claims and health claims on food labels and in advertisements $^{(14)}$. The standard specifies that nutrition content claims are claims about the content of certain nutrients or substances in a food, for example 'low in fat' or 'good source of calcium', while health claims refer to a relationship between a food and health. Food Standards Australia New Zealand (FSANZ) developed the Nutrient Profiling Scoring Criterion (NPSC) system to determine the eligibility of foods to make health claims. The NPSC model is based on the UK Ofcom model used to differentiate foods on the basis of their nutritional composition in the context of television advertising of foods to children ${ }^{(15)}$. Both models use the same simple across-the-board scoring system where points are awarded on the basis of the nutrient content per $100 \mathrm{~g}$ of a food or drink ${ }^{(15)}$. The key difference between the Ofcom and NPSC models is one additional category in the FSANZ model for cheese, edible oils, spreads and butter ${ }^{(14)}$. All foods carrying health claims in Australia and New Zealand must now meet the NPSC except special-purpose foods (infant formula products, infant foods, formulated meal replacements, supplementary sports foods and foods for special medical purposes), which are regulated separately in the Code ${ }^{(14)}$. The use of nutrient profiling to underpin New Zealand and Australia's health claims standard has been highlighted as an example of effective food policy ${ }^{(16)}$.

In NPSC, each product is first classified into one of three categories: (i) beverages (Category 1); (ii) cheese, oil, margarine and butter (Category 3); and (iii) any food other than those included in the previous two categories (Category 2). The NPSC score is then calculated by allocating baseline points for levels of risk-associated nutrients in a food (energy, saturated fat, total sugars and sodium); $\mathrm{V}$ points based on content of fruits, vegetables, nuts and legumes; protein points ( $\mathrm{P}$ points); and, in the case of Category 2 and 3 foods, fibre points (F points). The final score is derived using the formula: baseline points - (V points $)-(\mathrm{P}$ points $)-(\mathrm{F}$ points $)$ (see Appendix $)^{(17)}$. To qualify to display a health claim, Category 1 foods must have NPSC score less than 1, Category 2 foods must score less than 4 , and Category 3 foods must score less than 28. Lower scores therefore indicate a healthier product.

Our aim was to assess and compare the nutrient profile of packaged foods and non-alcoholic beverages available for sale in Australia and New Zealand in 2012. Eligibility to carry health claims and the relationship between NPSC score and the nutritional content of foods and beverages were evaluated.

\section{Methods}

Nutritional composition data were collected from labels of all packaged foods and non-alcoholic beverages available in two Auckland and four Sydney supermarkets during field surveys undertaken between February and December 2012. Standardised data collection methods were developed for an international collaborative project to compare and monitor the nutritional composition of packaged foods and have been described in detail previously $^{(18)}$. Supermarkets chosen for data collection in 2012 represented the biggest retail brands of the main supermarket retailers in each country ${ }^{(19)}$ (Foodstuffs $(54 \%$ of grocery market share) and Progressive Enterprises (38\% market share) in New Zealand; and Coles (25\%), Woolworths (32\%), Aldi (4\%) and IGA (9\%) in Australia) and were the largest stores in Auckland and Sydney for each brand. Nutrition information was recorded for all packaged supermarket products displaying a nutrition information panel, using smartphone tools developed by investigators $^{(20)}$. Products that did not carry a nutrition information panel, for example fresh produce, bakery and delicatessen items, were excluded. For each packaged product with a nutrition information panel, the brand name, product name and content of energy, protein, total fat, saturated fat, total carbohydrate, sugars, fibre and sodium per $100 \mathrm{~g}$ or $100 \mathrm{ml}$ were recorded electronically and subsequently converted to a Microsoft ${ }^{\circledR}$ Excel spreadsheet for analysis. Nutritional information recorded was for products 'as sold' (i.e. not 'as prepared') in order to maximise within-category product comparability (since preparation instructions vary and can have a significant impact on final composition); different pack sizes of the same product were recorded as separate items.

All data were checked and cleaned before analysis. Any data entry errors identified by value range and random sample checks were corrected using source data (product photographs). Special-purpose foods, alcohol, vitamins and supplements, and products that could not be categorised using the defined food classification system (mostly baking ingredients) were excluded from analysis. The FSANZ NPSC was used to determine a nutrient profile score for each product (Appendix). Following this, each product was assigned to one of fourteen predefined food groups using a classification system developed by the Global Food Monitoring Group ${ }^{(18)}$. Products were also allocated a variable specifying whether or not they qualified to carry a health claim.

Statistical analyses were performed using the SAS statistical software package version 9.3. All statistical tests were two-tailed and a $5 \%$ significance level maintained throughout the analyses. Proportions of foods meeting NPSC threshold values were summarised and mean NPSC scores were calculated. Data were analysed by country and food group and combined for overall analysis. Linear mixed models containing both fixed and random effects 
were used to evaluate the association between mean NPSC score and total energy, saturated fat, sugars and sodium, adjusting for country, food category and potential interaction effects.

\section{Results}

NPSC scores were derived for a total of 23596 packaged foods and non-alcoholic beverages: 15219 in Australia and 8377 in New Zealand. The smaller number of New Zealand products likely reflects fewer local supermarket retailers (just two retailers account for $92 \%$ of combined grocery market share ${ }^{(19)}$ ) and thus more homogeneity in food products compared with Australia. Food groups containing the largest number of products were (packaged) fruit and vegetables ( $n 3140,13 \%$ of total), dairy ( $n 3014,13 \%$ ) and sauces and spreads ( $n$ 2894, $12 \%$; Table 1 ).

\section{Nutrient profile of packaged foods available in Australia and New Zealand}

The mean NPSC score for all Australian and New Zealand foods combined was $7 \cdot 0$ (range -17 to 53 ; Table 1 ). NPSC Category 1 products (beverages) had the lowest scores (mean $-0 \cdot 6$, range -9 to 28 ) and Category 3 products (cheese, edible oils, spreads, margarines and butter) had the highest (mean 25.9, range 6 to 53). NPSC Category 2, which contained $86 \%$ ( $n 20313$ ) of products, had a mean score of 7.6 (range -17 to 34 ). By food group, edible oils had the highest mean NPSC score (25.9), followed by confectionery $(16 \cdot 2)$. Non-alcoholic beverages had the lowest mean score $(-0 \cdot 8)$, followed by fruit and vegetables $(-0 \cdot 3)$. Mean NPSC score for all New Zealand foods combined was 7.8 (range -16 to 45 ), while for Australia it was 6.6 ( -17 to 53 ). Across both countries, the food group with the largest variability in scores was edible oils (range 6 to 53), followed by dairy ( -7 to 36 ) and sauces and spreads ( -9 to 34 ).

\section{Proportion of foods eligible to carry health claims}

Forty-five per cent of all products met their respective NPSC threshold value, rendering them eligible to display health claims (Table 2). All eggs met the threshold value (100\%). Convenience foods (soup, pizza and ready meals; $82.5 \%)$ and fish and seafood products (80\%) were the next highest, while confectionery (9\%) and sugars, honey and related products (5\%) were the categories where fewest products met the threshold. Less than one-third of products in three staple food categories were eligible to carry health claims: dairy (32\%); meat and meat products (28\%); and bread and bakery (27.5\%).

Forty-seven per cent of Australian and $41 \%$ of New Zealand foods met their respective NPSC threshold value. The largest differences between Australia and New Zealand were for non-alcoholic beverages ( $64 \%$ and $48 \%$, respectively, met the NPSC threshold), snack foods (26\%

娾

$\stackrel{\Phi}{\infty}$

ナ O

돈

क

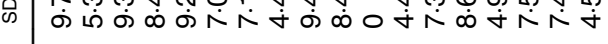

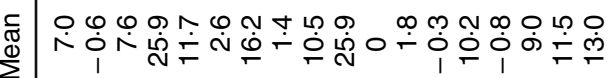

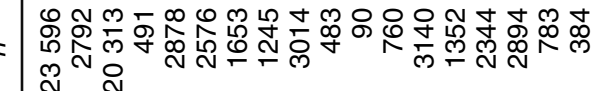

ํㅠㄴ

$\sum^{\infty}$

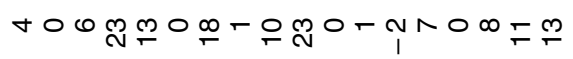

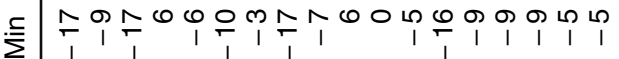

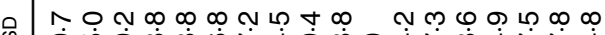

مि

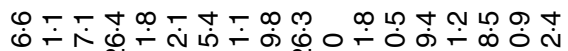

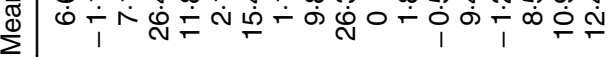

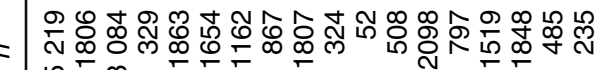
느

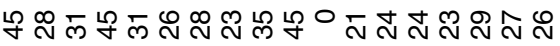

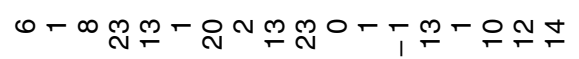

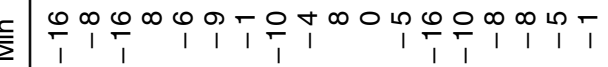

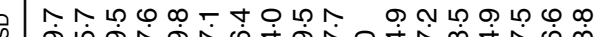

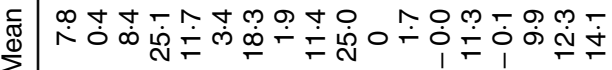

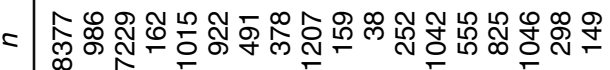




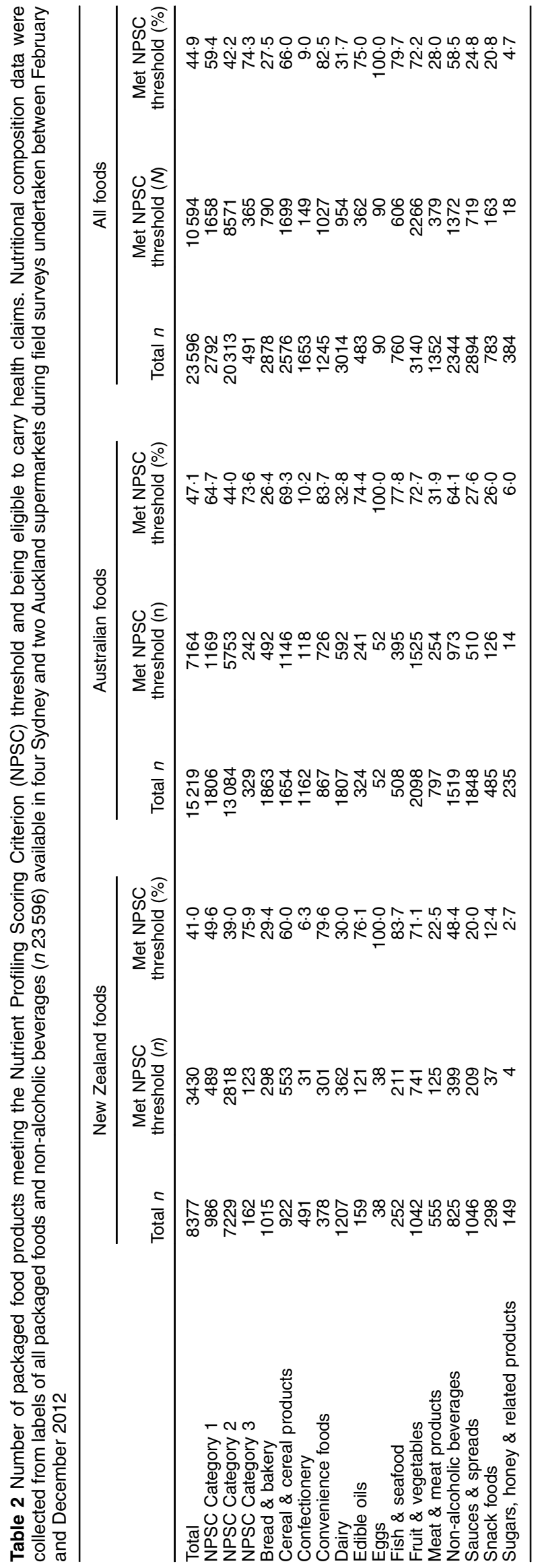

and $12 \%$, respectively) and meat and meat products (32\% and $22.5 \%$, respectively; Fig. 1 ).

\section{Association between changes in nutrient profile scores and energy, saturated fat, sugars and sodium} The mean energy content of all Australian and New Zealand foods combined was $1080 \mathrm{~kJ} / 100 \mathrm{~g}$ (range 0 to $4156 \mathrm{~kJ} / 100 \mathrm{~g}$ ) and $217 \mathrm{~kJ} / 100 \mathrm{~g}$ (range 0 to $2420 \mathrm{~kJ} / 100 \mathrm{~g}$ ) for non-alcoholic beverages, respectively. The mean saturated fat content of all products was $4.6 \mathrm{~g} / 100 \mathrm{~g}$ (range 0 to $98 \mathrm{~g} / 100 \mathrm{~g}$ ), and mean sugar and sodium contents were $14.3 \mathrm{~g} / 100 \mathrm{~g}$ (range 0 to $100 \mathrm{~g} / 100 \mathrm{~g}$ ) and $447 \mathrm{mg}$ / $100 \mathrm{~g}$ (range 0 to $19670 \mathrm{mg} / 100 \mathrm{~g}$ ), respectively.

Strong associations were found between variation in the NPSC score and the mean nutrient contents of foods (all $P$ values $<0 \cdot 0001)$. Model estimates showed that a twounit higher NPSC score (i.e. towards a less healthy nutritional profile) was associated with a higher mean energy density of $78(95 \%$ CI 76, 79) kJ/100 g. Similarly, a twounit higher NPSC score was associated with higher saturated fat $(0.95(95 \% \mathrm{CI} 0.94,0.97) \mathrm{g} / 100 \mathrm{~g})$, total sugars $(1.5(95 \%$ CI $1.5,1.6) \mathrm{g} / 100 \mathrm{~g})$ and sodium (66 (95\% CI 63, 69) $\mathrm{mg} / 100 \mathrm{~g})$ contents.

\section{Discussion}

Less than half of all packaged food products in Australian and New Zealand supermarkets were classified as healthy according to the FSANZ NPSC system. Across both countries, the mean NPSC score for all foods was 7.0; mean NPSC score for Australian foods (6.6) was lower (i.e. better nutrient profile) than for New Zealand (7.8). As such, Australia had a higher proportion of foods classified as healthy compared with New Zealand ( $47 \% v .41 \%$ ), largely driven by the healthier nutritional profile of Australian non-alcoholic beverages, snack foods, and meat and meat products.

The finding that less than half of the Australian and New Zealand packaged foods sampled were eligible to carry health claims has important implications given that a previous Australian survey found a high prevalence of nutrition content and health claims in particular product categories, including sports drinks (92\%), energy drinks (84\%), sports bars (57\%) and breakfast cereals $(54 \%)^{(21)}$. A more recent survey found that two-thirds of products in three categories (non-alcoholic beverages, breakfast cereals and cereal bars) carried at least one health or nutrition

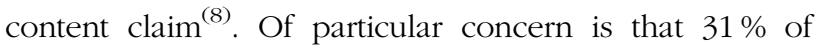
Australian products carrying health claims in 2011 did not meet NPSC criteria, suggesting a marked discrepancy between the current practice and the Standard ${ }^{(8)}$. Past research has shown that many consumers rely on displayed health claims to guide their food choices despite widespread concerns regarding their accuracy ${ }^{(8)}$. As such, the present study demonstrates a crucial need for regular, 


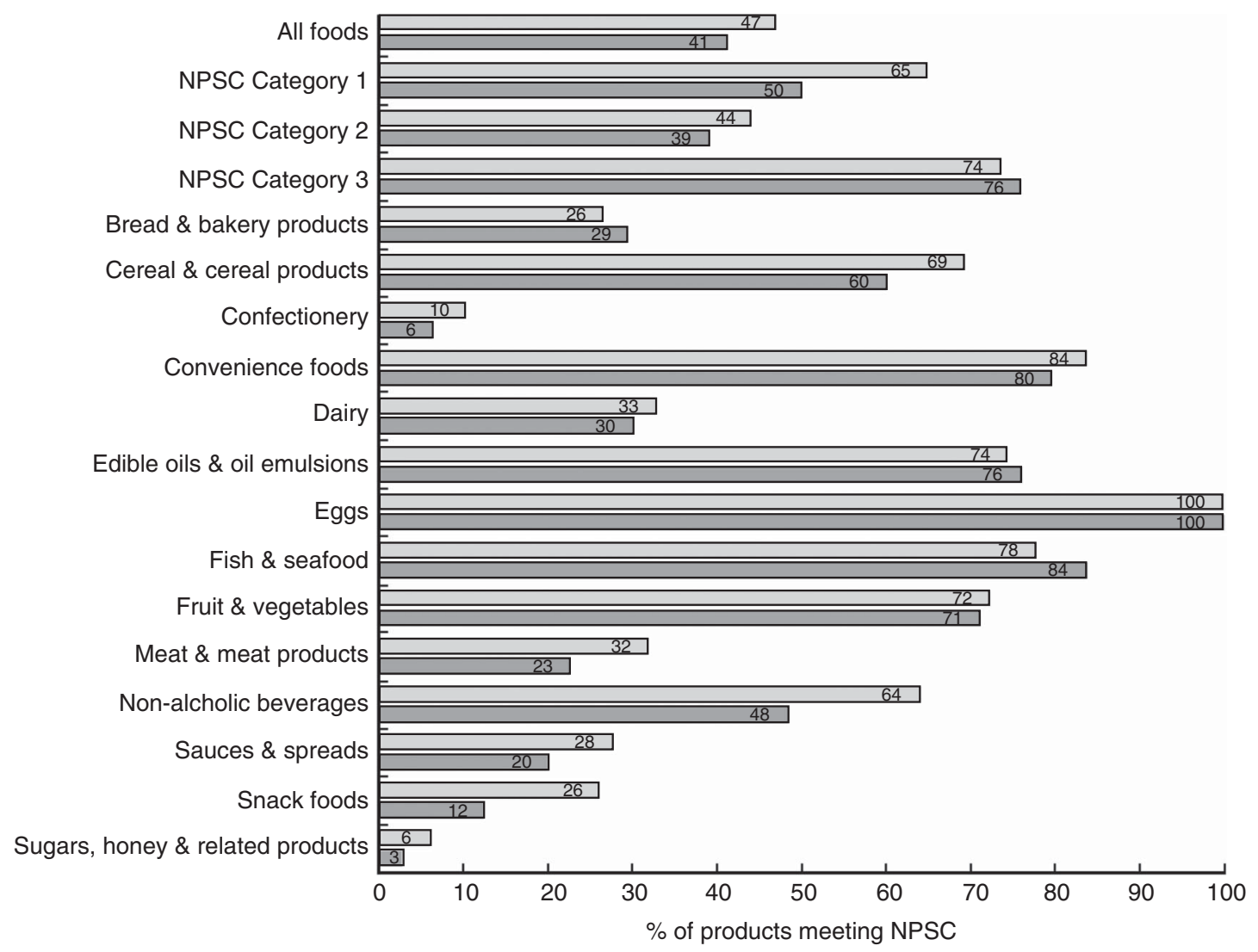

Fig. 1 Proportion of Australian $(\square)$ and New Zealand $(\square)$ packaged food products meeting the Nutrient Profiling Scoring Criterion (NPSC) threshold and being eligible to carry health claims. Nutritional composition data were collected from labels of all packaged foods and non-alcoholic beverages ( $n$ 23596) available in four Sydney and two Auckland supermarkets during field surveys undertaken between February and December 2012

independent monitoring of the nutritional composition and labelling of Australian and New Zealand foods to ensure adherence to the Standard ${ }^{(22,23)}$

We found positive associations between NPSC score and energy, saturated fat, sugar and sodium contents of packaged foods, in both unadjusted and adjusted models: for every two-unit higher NPSC score (i.e. towards a less healthy score) there was a corresponding increase in mean energy, saturated fat, sugar and sodium. This finding, along with the notable variability in product nutritional composition within food categories, indicates significant opportunity to improve population diets through product reformulation with a view to lowering energy density and levels of saturated fat, sugar and sodium. The UK salt reduction programme, which incorporated a major food reformulation strategy, is an example of the positive effects product reformulation programmes can have on nutritional content of foods and population $\operatorname{diets}^{(24)}$.

In addition to product reformulation, strategies are needed to help guide consumers towards healthier food choices. One potential approach is interpretive, frontof-pack nutrition labelling systems that provide simple, 'at-a-glance' nutrition information to consumers. Studies that modelled the potential impact of interpretive, front-ofpack nutrition labels on consumer food choices and obesity rates suggest that it would be a highly costeffective obesity-prevention strategy ${ }^{(6,25)}$. Australia and New Zealand recently announced plans to introduce a new voluntary Health Star Rating front-of-pack nutrition labelling system ${ }^{(26)}$. The scheme assigns a star rating to foods ranging from half (least healthy) to five (most healthy) stars based on the underpinning Health Star Rating nutrient profiling model, a modification of the NPSC $^{(26)}$. The Health Star Rating nutrient profiling system was based on the NPSC in order to ensure consistency between the two systems. Comprehensive monitoring of the food supply in both countries will be important to evaluate uptake of the voluntary Health Star Rating labels by the food industry and assess the impact of both nutrition labels and health claims on food product reformulation and consumption over time ${ }^{(22,23)}$.

Our investigation has several strengths. We conducted systematic surveys of packaged food products available for sale in Australia and New Zealand in 2012. Our data were collected from major supermarkets in the largest city in each country. We used standardised methods for data collection in both countries to ensure comparability and 
consistency of the food composition data collected and we used a regionally accepted standard (FSANZ NPSC) to define the nutritional quality of foods and their eligibility to carry health claims. In addition to assessing and comparing the nutrient profile of packaged foods in Australia and New Zealand, we also assessed their eligibility to carry health claims and quantified the relationship between nutrient profile score and nutritional content. Our study provides a comprehensive analysis of the packaged food supply in both countries prior to widespread introduction of health claims on foods and a new front-of-pack nutrition labelling system, and thus provides a useful baseline from which to evaluate the impact of these initiatives on the food supply. Future analyses will assess changes in the nutrient profile of the food supply over time for both countries.

Some limitations should be considered. Since only six supermarkets in total were sampled across both countries, our sample may not be representative of the true distribution of food products across the two countries. However, data collection occurred in major supermarkets in the largest city of each country, so our data are likely to represent a reliable sample of the packaged food products available in supermarkets throughout Australia and New Zealand. Further evidence to support this assumption comes from the FoodSwitch smartphone app which was launched in Australia and New Zealand using the food and nutrient databases employed for these analyses ${ }^{(17)}$. App users achieved a $70-80 \%$ success rate for food product scans, suggesting our data represent the majority of supermarket products available. Our analysis also included only packaged food products and fresh meat and produce were excluded. As such, the full food product range in Australia and New Zealand is likely to be healthier than our analysis suggests. Previous analyses of New Zealand supermarket sales reported that such variable-weight products accounted for approximately $10 \%$ of transactions ${ }^{(27)}$, thus packaged foods likely reflect a maximum of $90 \%$ of supermarket food products. We did not stratify our analysis by level of processing ${ }^{(28)}$; however, other New Zealand research has demonstrated a significant positive association between level of food processing and NPSC scores. Ultra-processed foods were found to have higher (less healthy) NPSC scores (11.63) than culinary processed foods (7.95) and minimally processed foods (3.27; CM Luiten, WE Waterlander, H Eyles et al., unpublished data).

We used NPSC to assess the nutritional quality of foods; however, a number of different nutrient profiling systems exist. Some are 'category specific' such as that proposed for regulation of nutrition and health claims in the $\mathrm{EU}^{(13)}$ while others, such as the UK Ofcom and FSANZ NPSC, are 'across the board' and rate all foods on the same scale ${ }^{(11)}$. A recent analysis of breakfast cereals in Germany and Norway used five different nutrient profiling models and found that $4-28 \%$ of cereals met respective model thresholds for health claims ${ }^{(29)}$. Despite differences in model design and algorithms, the NPSC and EU models appeared broadly similar in classifications (NPSC classified $23 \%$ of breakfast cereals as eligible to carry health claims compared with $28 \%$ using the EU model) and both classified more foods as eligible to carry health claims than the Keyhole, Ofcom and IWG models ${ }^{(29)}$.

Finally, our analyses were based on nutritional data provided on product nutrition information panels, which we assumed were accurate. Although we believe most companies endeavour to report correct nutritional values, this may not always be the case ${ }^{(30,31)}$. Some companies use accredited laboratories for analysis, but limited validation data make it difficult to know whether there are significant errors in the information provided on nutrition information panels ${ }^{(31)}$.

\section{Conclusions}

Our investigation, based on systematic surveys of food composition in two countries, provides a comprehensive, quantitative assessment of the nutrient profile of packaged foods in Australia and New Zealand. Our findings provide the basis for investigation of changes in food composition over time, comparisons with other countries around the globe, and evaluation of the impact of national policies on food availability and composition. In addition, our results highlight the few healthy packaged food choices currently available in key staple food categories. This work informs national and regional efforts to improve population diets.

\section{Acknowledgements}

Acknowledgements: The authors would like to thank Ashmita Chand and Mark Derksen for collecting and entering supermarket data in New Zealand supermarkets. Financial support: R.B. was supported by a University of Auckland summer studentship (funded by the University of Auckland). H.E. was supported by a Heart Foundation of New Zealand fellowship (\#1463). B.N. is supported by an Australian Research Council Future Fellowship (DP100100295) and a National Health and Medical Research Council of Australia Senior Research Fellowship (APP100311). The funders had no role in the design, analysis or writing of this article. Conflict of interest: None. Author contributions: C.N.M. formulated the research question, assisted with interpretation of the data and COwrote the article. R.B. designed the statistical analysis plan, conducted the data analysis and wrote the first draft of the article. Y.J. supervised the data analysis, assisted with interpretation of the data and provided feedback on the article. H.E. supervised the New Zealand supermarket data collections and data entry, assisted with interpretation of the data and provided feedback on the article. 
E.D. supervised the Australian supermarket data collections and data entry, assisted with interpretation of the data and provided feedback on the article. B.N. designed and is Principal Investigator of the Global Food Monitoring Study, supervised the Australian supermarket data collections, assisted with interpretation of the data and provided feedback on the article. All authors have seen and approved the final version submitted for publication. Ethics of buman subject participation: Ethical approval was not required.

\section{References}

1. Ministry of Health (2013) Health Loss in New Zealand: A Report from the New Zealand Burden of Diseases, Injuries and Risk Factors Study, 2006-2016. Wellington: Ministry of Health.

2. Global Burden of Disease Study (2010) GBD Profile: Australia. http://www.healthdata.org/sites/default/files/files/ country_profiles/GBD/ihme_gbd_country_report_australia.pdf (accessed August 2014).

3. Beaglehole R, Bonita R, Alleyne G et al. (2011) UN HighLevel meeting on non-communicable diseases: addressing four questions. Lancet 378, 449-455.

4. Zarocostas J (2011) WHO lists 'best buys' for cutting deaths from non-communicable disease. BMJ 342, d2648.

5. Slimani N, Deharveng G, Southgate DAT et al. (2009) Contribution of highly industrially processed foods to the nutrient intakes and patterns of middle-aged populations in the European Prospective Investigation into Cancer and Nutrition study. Eur J Clin Nutr 63, Suppl. 4, S206-S225.

6. Gortmaker S, Swinburn B, Levy D et al. (2011) Changing the future of obesity: science, policy, and action. Lancet $\mathbf{3 7 8}$, 838-847.

7. Devi A, Eyles H, Rayner M et al. (2014) Nutritional quality, labelling and promotion of breakfast cereals on the New Zealand market. Appetite 81, 253-260.

8. Hughes C, Wellard L, Lin J et al. (2013) Regulating health claims on food labels using nutrient profiling: what will the proposed standard mean in the Australian supermarket? Public Health Nutr 16, 2154-2161.

9. Kozup J, Creyer E \& Burton S (2003) Making healthful food choices: the influence of health claims and nutrition information on consumers' evaluations of packaged food products and restaurant menu items. J Mark 67, 19-34.

10. Van Trijpa H \& Van der Lansa I (2007) Consumer perceptions of nutrition and health claims. Appetite 48, 305-324.

11. Scarborough P, Arambepola C, Kaur A et al. (2010) Should nutrient profile models be 'category specific' or 'across-theboard'? A comparison of the two systems using diets of British adults. Eur J Clin Nutr 64, 553-560.

12. Sacks G, Rayner M, Stockley L et al. (2011) Applications of nutrient profiling: potential role in diet-related chronic disease prevention and the feasiblity of a core nutrientprofiling system. Eur J Clin Nutr 65, 298-306.

13. European Food Information Council (2008) Characterising the nutritional value of foods, using nutrient profiling. http://www.eufic.org/page/en/show/latest-science-news/ fftid/Characterising-nutritional-value-foods-nutrient-profiling/ (accessed December 2014).

14. Food Standards Australia New Zealand (2014) Australia New Zealand Food Standards Code - Standard 1.2.7 -
Nutrition, Health and Related Claims. http://www.comlaw. gov.au/Details/F2013L00054 (accessed August 2014).

15. Department of Health (2011) Nutrient Profiling Technical Guidance. London: Department of Health.

16. World Cancer Research Fund International (2014) Food Policy Highlights from Around the World. http://www.wcrf. org/int/policy/our-policy-recommendations/food-policyhighlights-around-world (accessed December 2014).

17. Dunford E, Trevena H, Goodsell C et al. (2014) FoodSwitch: a mobile phone app to enable consumers to make healthier food choices and crowdsourcing of national food composition data. JMIR mHealth uHealth 2, e37.

18. Dunford E, Webster J, Metzler A et al. (2012) International collaborative project to compare and monitor the nutritional composition of processed foods. Eur J Cardiovasc Prev Rehabil 19, 1326-1332.

19. Euromonitor PLC (2014) Passport Global Market Information Database. London: Euromonitor.

20. George Institute for Global Health (2014) Instructions for using the George Institute's Data Collection App Version 1.2. http://www.georgeinstitute.org/sites/default/files/instructionsfor-data-collector-app-for-supplement-database.pdf (accessed August 2014).

21. Williams P, Yeatman H, Ridges L et al. (2006) Nutrition function, health and related claims on packaged Australian food products - prevalence and compliance with regulations. Asia Pac J Clin Nutr 15, 10-20.

22. Neal B, Sacks G, Swinburn B et al. (2013) Monitoring the levels of important nutrients in the food supply. Obes Rev 14, 49-58.

23. Rayner M, Wood A, Lawrence M et al. (2013) Monitoring the health-related labelling of foods and non-alcoholic beverages in retail settings. Obes Rev 14, Suppl. S1, 70-81.

24. Wyness L, Butriss J \& Stanner S (2012) Reducing the population's sodium intake: the UK Food Standards Agency's salt reduction programme. Public Health Nutr 15, 254-261.

25. Sacks G, Veerman JL, Moodie M et al. (2011) 'Traffic-light' nutrition labelling and 'junk-food' tax: a modelled comparison of cost-effectiveness for obesity prevention. Int J Obes (Lond) 35, 1001-1009.

26. Ministry for Primary Industries (2014) Health Star Rating new food labelling system. Secondary Health Star Rating new food labelling system. http://www.foodsafety.govt.nz/ industry/general/labelling-composition/health-star-rating/ (accessed August 2014).

27. Hamilton S, Ni Mhurchu C \& Priest P (2007) Food and nutrient availability in New Zealand: an analysis of supermarket sales data. Public Health Nutr 10, 1448-1455.

28. Monteiro CA, Levy RB, Claro RM et al. (2010) A new classification of foods based on the extent and purpose of their processing. Cad Saude Publica 26, 2039-2049.

29. Maschkowski G, Hartmann M \& Hoffmann J (2014) Health-related on-pack communication and nutritional value of ready-to-eat breakfast cereals evaluated against five nutrient profiling schemes. BMC Public Health 14, 1178.

30. Food Safety Authority of Ireland (2010) Accuracy of Nutrition Labelling of Pre-packaged Foods in Ireland. Monitoring \& Surveillance Series. Dublin: Food Safety Authority of Ireland.

31. Food Standards Australia New Zealand (2009) Sodium Levels in a Range of Packaged and Takeaway Foods. http:// www.foodstandards.gov.au/publications/pages/sodiumlevels inarange4648.aspx (accessed December 2014). 


\section{Appendix}

\section{Nutrient profile score estimation metbod $(17)$}

Step 1. Determine the NPSC category of the food

- Category $1=$ Beverages

- Category $2=$ All foods not in Category 3

- Category $3=$ Cheese and processed cheese >320 mg $\mathrm{Ca} / 100 \mathrm{~g}$, edible oil, edible oil spread, margarine and butter

Step 2. Calculate baseline points

- 0-10 points for energy

- 0-30 points for saturated fat

- 0-10 points for sugars

- 0-30 points for sodium

- Calculate total baseline points $=\mathrm{X}+\mathrm{X}+\mathrm{X}+\mathrm{X}$
Step 3. Calculate modifying points

Fruit and vegetable points (V points; 0, 1, 2, 5 or 8)

- Formula used: (\% non-concentrated FVNL) $+(2 \times \%$ concentrated fruit or vegetables $) \div(\%$ nonconcentrated FVNL $)+(2 \times \%$ concentrated fruit or vegetables $)+(\%$ non-FVNL ingredient $) \times 100 / 1$

Protein points ( $\mathrm{P}$ points)

- Calculate protein points (1-5)

Fibre points (F points)

- Calculate fibre points (1-2)

Step 4. Calculate the final score

Final score $=$ Baseline points $-(\mathrm{V}$ points $)-(\mathrm{P}$ points $)-$ (F points)

Data availability and imputation for nutrient profile scoring

\begin{tabular}{|c|c|}
\hline Nutrient & Availability \\
\hline $\begin{array}{l}\text { Energy } \\
\text { Protein } \\
\text { Total sugar } \\
\text { Saturated fat } \\
\text { Sodium } \\
\text { Dietary fibre }\end{array}$ & $\begin{array}{l}\text { Complete } \\
\text { Complete } \\
\text { Complete } \\
\text { Complete } \\
\text { Complete } \\
\text { Partial data were available: } \\
\text { - Products in a food category known not to contain fibre (e.g. eggs) were assigned a fibre score of } 0 \\
\text { - Products with data available were assigned an individual fibre score } \\
\text { - Products with no data but in a category of foods known to contain fibre were assigned an imputed } \\
\text { value. The imputed value was the average for all products in the category with data }\end{array}$ \\
\hline Calcium & $\begin{array}{l}\text { Partial data were available for the cheese and processed cheese categories which require a calcium } \\
\text { value for the calculation of the nutrient profile score: } \\
\text { - Products with data available were assigned an individual calcium score } \\
\text { - Products with missing data were assigned an imputed value. The imputed value was the average } \\
\text { for all products in the category with data }\end{array}$ \\
\hline $\begin{array}{l}\text { Percentage content of fruit, } \\
\text { vegetables, nuts and legumes } \\
\text { (FVNL; V points) }\end{array}$ & $\begin{array}{l}\text { No data were available: } \\
\text { - Products in food categories known not to contain appreciable amounts of fruit and vegetables (e.g } \\
\text { dairy milk) were assigned a V points value of } 0 \\
\text { - Products in food categories known to contain fruit and vegetables were assigned imputed } \\
\mathrm{V} \text { points values }\end{array}$ \\
\hline
\end{tabular}

